\title{
Ferro arrependido: um panorama da recepção de Eça de Queirós em 1945
}

\author{
Regretful Ferro: An overview of Eça de Queirós's reception in 1945
}

\author{
Izabel Margato* \\ Pontificia Universidade Católica do Rio de Janeiro \\ Rio de Janeiro, RJ, Brasil \\ Breno Góes** \\ Pontifícia Universidade Católica do Rio de Janeiro \\ Rio de Janeiro, RJ, Brasil
}

\begin{abstract}
Resumo: Este trabalho consiste em uma leitura do discurso "O Centenário de Eça de Queirós”, de António Ferro. Trata-se de uma fonte que permite que se trace um panorama das comemorações do primeiro centenário de nascimento de Eça, bem como um esquema do contexto histórico-político que cercou essa efeméride, marcado pela primeira grande crise do salazarismo em Portugal. O objetivo da análise é demonstrar como a produção sobre o autor neste momento teve sucesso em sua tentativa de desafiar o discurso monológico oficial e fundar em torno de Eça de Queirós um debate estético e político.
\end{abstract}

Palavras-chave: António Ferro; Estado Novo português; Eça de Queirós;

\begin{abstract}
This work consists in an analysis of the speech "O Centenário de Eça de Queirós", by António Ferro. This source allows one to trace an overview of the celebrations of Eça's first centenary of birth, as well as a scheme of the historical-political context that surrounded the event, marked by the first great crisis of Salazar's regime in Portugal. This work aims to demonstrate how the production about Eça in this moment succeeded in it's attempt to defy the monological discourse of the government and found a political and aesthetical debate around Eça.
\end{abstract}

Keywords: António Ferro; portuguese Estado Novo; Eça de Queirós;

\section{INTRODUÇÃO}

Este artigo procura apresentar resultados ainda bastante parciais de uma pesquisa a respeito do primeiro centenário de Eça de Queirós, celebrado no ano de 1945. Esse evento, conforme escreveu o célebre professor Ernesto Guerra da Cal, foi marcado por uma "avalanche" (CAL, 1969, p. 69) de obras a respeito do autor de Os Maias, produzidas sobretudo em Portugal e no Brasil.

\footnotetext{
* Doutora em Letras, Bolsista de Produtividade em Pesquisa 1C do CNPq, Professor Associado II da PUCRio. E-mail: izabelmargato@gmail.com

** Estudante de doutorado do Programa de Pós-graduação em Literatura, Cultura e Contemporaneidade da PUC-Rio, bolsista CNPq. E-mail: brenocesargoes@gmail.com.
} 
Embora ainda não haja um estudo de fôlego que tome como objeto a efeméride, há no mínimo dois trabalhos que se detém de alguma forma sobre ela, e que merecem ser aqui mencionados de partida, pois é em relação a eles que pretendemos fazer surgir o contorno da perspectiva que aqui se propõe. O primeiro a que queremos nos referir (embora seja o segundo na ordem cronológica) é o artigo "Os Três Antônios: a recepção de Eça na década de quarenta", de Giuliano Ito. O texto concentra-se em fazer uma análise comparativa de obras críticas sobre Eça de três importantes autores que o pensaram durante o centenário: António Sérgio, António Cândido e António José Saraiva. $\mathrm{Na}$ parte final do texto, quando contextualiza as obras em relação ao período histórico em que foram produzidas, Ito inclui uma recomendação (ITO, 2012, pp. 118, 119):

[...] a comparação entre ensaios recorrentemente citados em trabalhos sobre o escritor serve para demonstrar como a situação histórico-social influencia no teor das análises literárias e isso não pode deixar de ser levado em conta quando um crítico, nos dias de hoje, utiliza esses ensaios como pressuposto para seu trabalho.

A "situação histórico-social" referida por Ito é, em verdade, a dramática situação política do Portugal de 1945, sob a ditadura de António Salazar. Uma reflexão sobre essa situação contextual também norteia o segundo trabalho que deve ser mencionado aqui: o extraordinário livro O Último Eça, de Miguel Real (2006), que propõe uma nova periodização da obra de Eça de Queirós e uma ressignificação do que seria a porção final de sua produção. Mais severo do que Ito, Miguel Real não se restringe a ressaltar a importância da contextualização das obras daquele período, mas chega ao ponto de compreender que aquilo que foi escrito sobre Eça por volta de seu centenário encontrase irremediavelmente prejudicado por carregar marcas da disputa política de então. Segundo Real (2006, p. 75), a maioria dos autores do período no qual estaria compreendido o centenário estaria intoxicada por diversas formas de "preconceito ideológico", e, portanto, não analisaria a obra de Eça

[...] em si e por si, ontologicamente reduzida a um corpus textual, mas segundo uma bitola de valores [...] de que Eça se aproximaria em certas fases e se afastaria noutras. Tal escala axiológica, mais do que retratar fidedignamente o pensamento do autor em cada uma das suas fases e segundo os textos da sua obra, afirma-se como projecção da interpretação pessoal do comentador relativamente à história de Portugal e/ou à história da literatura portuguesa.

Vemos, portanto, que tanto Ito quanto Real acabam por chamar a atenção para a legibilidade de certo momento histórico em algumas importantes obras sobre Eça de Queirós produzidas em seu centenário. No entanto, se Ito se restringe a apontar essa legibilidade, Real acusa-a de prejudicar a fidedignidade da obra, enquanto crítica literária.

O presente texto, bem como a pesquisa mais larga na qual ele se insere, podem ser descritos como uma análise complementar ao trabalho de Ito, e diametralmente oposta à perspectiva de Miguel Real (embora reconhecendo o brilhantismo e a importância de seu livro): o que se pretende aqui é investigar de que forma o momento histórico conturbado 
no qual ocorreu o primeiro centenário de nascimento de Eça de Queirós pode ser ele próprio lido nas entrelinhas dos textos ali produzidos. Dito de outra forma: não interessa aqui o que autores de 1945 tinham a dizer "ontologicamente" sobre Eça de Queirós, mas sim o que eles conseguiam enxergar no autor oitocentista que tornava tão urgente e relevante discuti-lo cem anos após seu nascimento, em um momento dramático da história portuguesa.

Para este texto, que é a primeira apresentação de resultados desta pesquisa, e portanto deve ter um caráter introdutório, optamos por mergulhar no discurso "Eça de Queirós no Centenário de seu Nascimento", proferido por António Ferro já em 1946 e publicado três anos depois. Essa escolha é motivada pelo fato de Ferro fazer de seu discurso uma espécie de balanço oficial das comemorações do centenário de Eça, e pelo fato de ele aludir frequentemente, como se verá, às disputas políticas então em causa; uma tal abrangência do texto permite que se faça dele o ponto de partida para uma espécie de "vista panorâmica" da efeméride. Ou, por outra, permite construir uma nova história de "três Antônios": apenas, neste caso, eles se chamarão António Ferro, António Eça e pairando sobre tudo, mais subentendido do que de fato presente - António de Oliveira Salazar.

\section{O PRIMEIRO ARREPENDIMENTO}

António Ferro, o poderoso diretor do $\mathrm{SNI}^{1}$, tinha no mínimo dois motivos para estar arrependido na noite invernal de quatro de fevereiro de 1946, quando o automóvel que o conduzia atravessou o Chiado lisboeta e freou no Largo Rafael Bordalo Pinheiro, em frente à sede do Círculo Eça de Queirós. Ferro, que fundara e presidia esse "Círculo" (na realidade um elegante clube social e literário frequentado pela elite lusitana) trabalhara bastante nos anos anteriores para que o lugar estivesse tão concorrido e luxuoso quanto naquela noite. Agora que o momento chegara, contudo, os seus dois arrependimentos eclipsavam o fato da sede do Círculo estar repleta de convidados poderosos e elegantes (figuras que Salazar gostava de chamar de o "escol"'2 português), todos ansiosos para o baile de logo mais; ${ }^{3}$ nem foi capaz de empolgá-lo a pequena orquestra que, por capricho seu, preparava-se para mais tarde executar peças dançantes da virada do século, com os músicos vestidos em roupas de época; Ferro não relaxou o cenho sequer diante da bela

\footnotetext{
1 O Secretariado Nacional de Informação, Cultura Popular e Turismo de Portugal. Até 1945, o órgão chamou-se Secretariado de Propaganda Nacional, tendo portanto como sigla SPN.

${ }^{2}$ Uma das marcas distintivas do salazarismo em relação a outros regimes fascistas foi seu elitismo. Embora não abdicasse de políticas de massa em âmbitos como a educação e a propaganda, Salazar sempre atribuiu grande importância ao fortalecimento de uma elite oligárquica que não apenas funcionasse como mediação corporativa do regime com o restante do país, mas também servisse como exemplo para os demais em campos como o gosto, as artes e as relações trabalhistas. Salazar referia-se a essa elite como o "escol" do país. A esse respeito, cf. ROSAS, Fernando. "O salazarismo e o homem novo: ensaio sobre o Estado Novo e a questão do totalitarismo" Análise Social, vol. XXXV (157), 2001, 1031-1054. p. 1039

${ }^{3}$ Para esta e todas as demais informações factuais contidas neste parágrafo a respeito da noite em questão, conferir (1946), "As comemorações do centenário queirosiano encerraram-se ontem com um serão no Círculo Eça de Queirós", Terça, 5 de Fevereiro de 1946, CasaComum.org, Disponível HTTP:

http://www.casacomum.org/cc/visualizador?pasta=09795.118 (2019-8-14)
} 
presença da atriz e poeta Maria Manuela do Couto Viana, ainda que ela (que usualmente se apresentava em trajes de camponesa folclórica minhota, para melhor exaltar os valores da pátria e do regime) naquela noite tivesse aceitado vestir-se com uma "deliciosa" toilette de luxo evocativa dos anos 1880.

O primeiro arrependimento de Ferro era muito simples: ele tinha afazeres importantes aos quais não estava dando atenção para estar ali. A festa extravagante daquela noite assinalava o final das comemorações estatais do primeiro centenário de nascimento do escritor oitocentista Eça de Queirós, que dava nome ao Círculo, e consistia em um evento de grande repercussão. O centenário vinha sendo comemorado com pompa e circunstância pelo SNI desde novembro de 1945, com uma grande exposição no Grêmio dos Escritores e uma reedição oficial das obras de Eça, entre outros eventos. ${ }^{4}$ A época em que as preocupações mais sérias de Ferro se resumiam a organizar efemérides literárias, contudo, havia ficado para trás. Agora, noites como aquela seriam mais produtivas se fossem gastas na administração da grave crise que seu secretariado enfrentava, desde que o cerco dos Aliados fechara-se sobre Berlim e o "Reich de mil anos" 5 terminara muito antes do tempo previsto. O fim da Segunda Guerra Mundial sepultou a hipótese de uma Europa hegemonicamente fascista, e colocou o governo de Salazar na posição desconfortável de ser uma das únicas ditaduras de inspiração totalitária em meio a uma Europa ocidental majoritariamente democrática. O Estado Novo português, sob o olhar pressuroso da Inglaterra e dos Estados Unidos, via-se forçado a fazer concessões econômicas e políticas, abandonando (ou aparentando abandonar) práticas e instituições demasiado semelhantes às do Eixo fascista; por outro lado, era necessário manter longe de ideias revolucionárias as oposições e as forças armadas do país, que poderiam conspirar para apear Salazar do poder se notassem muitos sinais de fraqueza (ROSAS, 2018, pp. 221-235).

Justamente ele, Ferro, que desde 1920 se dizia "um admirador do fascismo" (RAIMUNDO, 2015, p. 20) - tendo inclusive sugerido o regime de Mussolini como um modelo para o Estado Novo nascente em Portugal, em artigo de 1932 (FERRO, 2003, pp. 228-231) - tornara-se o maior responsável por esconder sinais de fraqueza do ditador. Convidado em 1933 para implementar e dirigir o SPN (Secretariado de Propaganda Nacional), o jornalista fez dele "um sistema de propaganda e inculcação ideológica autoritária e monolítica” (ROSAS, 2018, p. 333) semelhante às experiências promovidas por Joseph Goebbels na Alemanha e Dino Alfieri na Itália, trabalhando sempre para fortalecer a imagem do chefe da Nação. Ferro cooptou artistas e intelectuais (TORGAL, 2003), censurou adversários (VICTORINO, 2013) e estabeleceu laços com quem pode da intelectualidade de extrema direita ao redor da Europa (RIBEIRO, 2011; SANTOS, 2016) para disseminar em Portugal e no mundo certa imagem de Salazar: a do "chefe sereno, sábio, paternal, austero, vigiando na sua distância, no seu isolamento heróico, sobre essa 'boa gente alegre, trabalhadora (...) para a levar pelo bom caminho" (ROSAS,

\footnotetext{
${ }^{4}$ Para essa informação, cf. (1945), "Eça de Queirós nas salas do Grémio Literário", Sexta, 23 de Novembro de 1945, CasaComum.org, Disponível HTTP: http:/ / www.casacomum.org/cc/visualizador?pasta=09795.107 (2019-8-14)

${ }^{5}$ Maneira megalomaníaca através da qual Adolf Hitler e a propaganda nazista se referiam ao regime nazista na Alemanha.
} 
2018, p. 170). Agora, em 1946, os ventos que sopravam da Europa e da América do Norte ameaçavam derrubar essa cuidadosa construção de mais de uma década, trazendo de volta a hipótese da democracia e - supunha Ferro - tudo aquilo que ele considerava como negativo desse regime: a ambiguidade, a incerteza e a artificialidade. A crise era tão palpável que, mesmo numa noite como aquela, festiva, o diretor do SNI inseriu uma alusão discreta mas inconfundível às forças emergentes do pós-guerra em seu discurso oficial (FERRO, 1949, p. 26):

Vivemos numa época mais mentirosa ainda, possivelmente, do que a época em que viveu o grande romancista [Eça de Queirós]! (...) Quando ouvimos os discursos, as declarações, as entrevistas, de alguns políticos do nosso tempo, quando assistimos, como espectadores, as reuniões internacionais, parece-nos assistir à montagem duma grande, gigantesca peça onde os atores raramente são naturais.

Não havia, contudo, qualquer hipótese de Ferro não estar ali naquela noite, para a celebração daquele escritor, não importando a gravidade de seus outros problemas: uma pessoa que Ferro conhecera muito anteriormente, no contexto da chegada de Salazar ao poder, era justamente quem o obrigava agora, por dever de honra, a comemorar com extravagância o centenário do nascimento de Eça de Queirós. Consistia em uma pequena ironia do destino, inclusive, que, naquele momento dramático em que o regime balançava perigosamente estivesse no Círculo alguém cuja ligação com Ferro remontava à origem daquele mesmo regime. A história corre assim: ainda em 1933, quando fora incumbido por Salazar da tarefa de desarticular o movimento Nacional-Sindicalista (uma organização fascista aos moldes dos Camisas Negras italianos, que convinha ao ditador dissolver e absorver no seu próprio governo, neutralizando o líder rival), Ferro pedira ajuda justamente a um jovem funcionário seu do SPN, que cerrava fileiras com o líder NacionalSindicalista Rolão Preto, mas estava disposto a trair o movimento. Tratava-se de ninguém menos que António Eça de Queirós, o filho do consagrado romancista. António Eça, em conluio com Ferro e outros intelectuais, insuflou uma debandada nas hostes nacionalsindicalistas ao fundar a milícia "Acção Escolar Vanguarda" (futura Mocidade Portuguesa), alinhada ao salazarismo, que esvaziou o movimento rival e contribuiu decisivamente para a ida de Rolão Preto para o exílio (MEDINA, 1978; PINTO, 1994). Desde essa altura, o jovem Eça tornou-se braço direito do diretor do SPN e, em numerosas ocasiões, o representante do salazarismo no estrangeiro (Schiró, 2015). Essa intensa e longeva parceria, que em 1943 fora fortalecida com a promoção de António Eça para o cargo de subdiretor do SPN, obrigava Ferro a agora dedicar-se com especial esmero àquela celebração do centenário do autor de Os Maias.

Não se quer dizer com isso que uma efeméride desse porte não justificasse por si mesma a celebração. $\mathrm{Na}$ medida em que Eça de Queirós era naquele momento um autor português imensamente conhecido em outros países, traduzido para diversos idiomas, um verdadeiro ídolo no Brasil - mas objeto também de uma grande consagração em Portugal - seu centenário não poderia ser ignorado. A escolha de Ferro foi a de instrumentalizálo: especialmente em um momento de crise como aquele, cabia ao seu órgão de propaganda reapresentar Eça como escritor com ideias afinadas às do regime, que em 
suas páginas exaltava valores como o nacionalismo patriota, o moralismo, o catolicismo e o horror à democracia. Ferro e António Eça organizaram a já referida exposição sobre Eça de Queirós no Grêmio Literário de Lisboa: ela salientava o quanto o escritor fora um bom cristão e um bom pai de família, o quanto as questões políticas sociais com as quais se batera pertenciam a um passado morto e, principalmente, "evocava carinhosamente o português que Eça de Queirós teimosamente quis ser - lutando contra a desnacionalização de sua pátria". ${ }^{6}$ Décadas depois, o historiador Luís Benjaja de Schiró haveria de descrever esse movimento de Ferro e António Eça como uma tentativa de converter Eça de Queirós em um “apoiante post mortem do Estado Novo” (SCHIRÓ, 2105, p. 1102).

\section{O SEGUNDO ARREPENDIMENTO}

O problema (e aqui chegamos finalmente ao segundo motivo para o arrependimento de António Ferro naquela noite) é justamente que, no que diz respeito a essa missão de "conversão", as comemorações daquele centenário pareciam ter fracassado. Ferro estava perplexo: a prática de cooptar a memória de ícones literários da pátria descobrindo-lhes feições nacionalistas ou moralistas havia dado perfeitamente certo com Camões, por exemplo, sem que houvesse grande manifestação contrária. (VICHINSKI, 2015) Uma de suas principais preocupações enquanto chefe do SPN, inclusive, fora a de blindar o regime de contestações no campo cultural, ao estabelecer uma relação corporativa com a intelectualidade portuguesa - distribuindo cargos, patrocínios e prêmios que garantissem a lealdade dos artistas, acadêmicos e formadores de opinião (RAIMUNDO, 2015). É verdade que o projeto dera apenas parcialmente certo: muitos acadêmicos e artistas plásticos aderiram, bem como cineastas, mas quase ninguém do campo literário. Ferro contava que sobre esse setor menos colaborativo especialmente sobre a então recém nascida e já muito combativa literatura neorrealista pairaria sempre a força coerciva da PVDE (polícia política do regime, rebatizada no próprio ano de 1945 como PIDE). O tema do centenário de Eça, contudo, inesperadamente serviu de bandeira em torno da qual se agruparam as mais distintas vozes dissidentes do regime, ousando fazer contraponto ao discurso oficial. Era difícil compreender o motivo: segundo o próprio Ferro diria em seu discurso, Eça jamais fora um "revolucionário de cabeleira revolta" (FERRO, 1949, p. 17), tampouco um "sans coulotte de punhos cerrados" (FERRO, 1949, p. 17), sua obra não era nenhum panfleto partidário. Por que justamente em torno dele o dissenso?

Ferro não sabia. O fato era que uma massa jamais suspeitada de queirosianos de última hora surgiu do nada para publicar trabalhos naquele ano de 1945, frequentemente atravessados por discursos subversivos: um jovem estudante aveirense, de nome Mário Sacramento - que já havia sido preso pela PVDE em 1938, e militava no clandestino Partido Comunista Português (VOUILLOT, 2011) - publicou um denso volume

\footnotetext{
${ }^{6}$ Todas as informações a respeito da exposição oficial no Grêmio Literário foram retiradas de (1945), "Eça de Queirós nas salas do Grémio Literário", Sexta, 23 de Novembro de 1945, CasaComum.org, Disponível HTTP: http:/ /www.casacomum.org/cc/visualizador?pasta=09795.107 (2019-8-14)
} 
intitulado Eça de Queirós - Uma estética da Ironia (1945), associando certos procedimentos estéticos do autor oitocentista à "revolução permanente", conceito de Marx e Engels muito em voga nas esquerdas de então por conta do trabalho de Leon Trotsky (SACRAMENTO, 1945, p. 91):

É Eça quem pela primeira vez entre nós fala de revolução permanente. Deste modo, Revolução e Ironia são imagens de um mesmo processo, desenrolado, um, no plano da consciência, o outro, no plano do social. E a sua função, como ironista e como revolucionário, estará em compreender e catalizar, em adotar uma pedagogia que não pretenda nortear, mas suscitar;

Mais grave era o caso do editor da revista modernista Presença, João Gaspar Simões: ele, que jamais demonstrara qualquer interesse na prosa realista do século XIX, agora surgia com uma imensa biografia intitulada Eça de Queirós: o homem e o artista (SIMÕES, 1945). Sob o verniz respeitável do gênero biográfico, a obra verdadeiramente consistia em uma tentativa de estudo da vida, da obra e da personalidade do biografado à luz dos estudos psicanalíticos do dr. Sigmund Freud, no qual não faltavam sugestões de que Eça teria nutrido uma paixão incestuosa pela própria mãe, entre outros desejos vindos do seu "inconsciente" - tudo extremamente incompatível com a figura respeitável, sóbria e muito decente que o Estado Novo procurava fixar (SIMÕES, 1945, p. 36):

E o pequeno José Maria, que até aí vivera entre velhos e gente boçal, sente um deslumbramento perante aquela mulher que lhe dizem ser sua mãe. Então, nasce do fundo de seu coração uma paixão ardente e indefinível, que durará toda a vida. A revelação do seu nascimento deve tê-lo despertado cedo para os mistérios da vida sexual.

Talvez o caso mais decepcionante para Ferro tenha sido o do filósofo Francisco Vieira de Almeida, que - ao contrário dos outros rebeldes citados - era um acadêmico consagrado, já possuía cabelos grisalhos e afinal de contas era até monarquista. Pois bem: Vieira de Almeida publicara naquele ano de 1945 um livro sobre Eça, intitulado À Janela de Tormes, que não apenas disfarçava pouco o seu verdadeiro caráter de libelo antifascista (brandia a liberdade intelectual de Eça como um símbolo contra os regimes totalitários) como também aproveitava para fazer críticas à forma como o Estado Novo escolhera comemorar o centenário, comparando o regime de Salazar ao ridículo personagem Conselheiro Acácio, de O Primo Basílio: "Acácio do tempo de Eça literatejava mas temia. $\mathrm{O}$ atual garimpa soberbo, e se Eça agora vivesse Acácio não o deixaria escrever; para disfarçar, celebra-o" (ALMEIDA, 1945, p. 32).

Isso para não falar do fogo amigo. Setores conservadores da Igreja Católica, com quem o salazarismo sempre cultivara uma aliança mutuamente produtiva (SIMPSON, 2014), não se preocupavam nem remotamente em endossar a figura de Eça pintada pela propaganda oficial. Ao contrário: dois padres - Pe. Allyrio de Mello e Pe. João Mendes produziram cada um o seu pequeno volume escrito em tom exaltado, censurando a adoração em torno de Eça e demolindo absolutamente todos os aspectos da obra do escritor; Mello, especialmente, encerrava seu livro sem deixar pedra sobre pedra (MELLO, 1945, pp. 249, 250): 
[...] perante tantas cenas inverossímeis e tantas personagens impossíveis; em face de teses tão inconsequentemente conduzidas, e de princípios expostos sem o mínimo fundamento; diante de profecias de derrocada que não se cumpriram, e de caricaturas que representam deformações de pessoas; em frente da maneira como tantas vezes encarou a Pátria, a Humanidade e o próprio Deus; e, acima de tudo talvez, dada a sua negação expressa da liberdade no homem, e pessimismo torvo e derrotista que lhe enegrece tantos livros, naturalmente acodem aos bicos da pena, para julgar na sua generalidade a obra de Eça de Queiroz, aquelas mesmas palavras com que ele julgou a 'arte idealista': "É uma quimera, não é um ser vivo" [...]

Acuado, mas sem condições de melindrar mais os importantes aliados do clero, Ferro não teria outra saída, a não ser aproveitar o discurso daquela noite para oferecer humildemente a outra face (FERRO, 1949, p. 17):

Aceitamos e respeitamos a posição dos católicos, por exemplo, quando se manifestam contra certos aspectos da celebração deste Centenário (...) não lhes é fácil esquecer-se - e compreende-se - a liberdade de certas pinturas de Eça de Queirós, o à vontade de algumas das suas opiniões e conceitos, até aquela aparentemente obsessão anticlerical, revelada, sobretudo, em $O$ Crime do Padre Amaro e $A$ Relíquia. $\mathrm{O}$ combate de alguns católicos às Comemorações, e sobretudo à forma como seriam encaminhadas, foi natural, íamos quase a dizer justo. Mas as suas restrições à obra de Eça de Queirós não impedem - e os próprios católicos o reconhecem - que o devamos considerar um valor indiscutível.

O caráter contraditório do texto acima é evidenciado se o resumimos na seguinte fórmula: “aceitamos que os católicos discutam Eça, mas ele é indiscutível". Esse paradoxo, além de salientar a dependência que o Estado Novo tinha do catolicismo conservador, revela-nos hoje também as intenções mais sinceras do regime: o termo "indiscutível" sempre fora um dos mais caros ao salazarismo, desde quando em um discurso de 1936 o próprio António Salazar apresentara os valores do regime em torno da noção de indiscutibilidade: "Não discutimos Deus e a virtude; não discutimos a Pátria e a sua História; não discutimos a autoridade e o seu prestígio" (SALAZAR, 1945, p. 130), etc. Esse discurso deixa mais claro do que nunca que a preocupação que o regime apresentou de laurear, louvar e dar visibilidade a certos valores que the eram caros (como esses que Salazar cita acima) jamais pode ser confundida com uma vontade de que esses valores fossem de fato debatidos e apropriados pela sociedade portuguesa. Debates implicam sempre na colocação de uma ideia em relação à outra; essa relativização, por sua vez, implica em um risco de dessacralização - ou desnaturalização - da ideia original, num processo que pode inclusive transformá-la. Cabe aqui lembrar a reflexão de Hannah Arendt sobre o totalitarismo: segundo a autora (ARENDT, 1989, pp. 512-513), aos governos de pretensão totalitária - cuja força provém justamente da crença de que aquele não é um governo assente em certas ideias políticas transitórias e contingentes, mas em valores naturais, puros e imutáveis, como são as leis da física e da natureza, em geral interessa apenas a exaltação. Era o caso do regime de Salazar: nas palavras do historiador Luís Trindade, "o Estado Novo é já o tempo da celebração, e não do combate" 
(TRINDADE, 2008, p. 15). E, no entanto, lá estava Eça - quarenta e cinco anos depois de sua morte e doze anos depois da ascensão de Salazar - transformado no objeto de um combate feroz, discutido em seus mínimos aspectos, no centro de uma polêmica envolvendo o regime, a oposição e a Igreja.

Ferro não tinha ninguém além de si para culpar por aquela confusão. O discurso nacionalista que fora se tornando hegemônico no âmbito da intelectualidade, ao longo das primeiras décadas do século XX português (TRINDADE, 2008), havia feito um trabalho consistente no sentido de naturalizar Eça de Queirós, fazendo esmaecer seus aspectos mais polêmicos: muito antes de Ferro, outros intelectuais já haviam sido bem sucedidos na tarefa de associar a escrita de Eça a valores como o patriotismo, a moral e o cristianismo. Agostinho de Campos, por exemplo, um dos intelectuais mais simbólicos desses anos, fizera publicar em 1922 uma antologia da obra de Eça (CAMPOS, 1922) adequada para "a família e a escola", com o propósito explicitado em prefácio de censurar ("disfarçando como convém disfarçar, intervindo a tempo na defesa dos princípios morais" [CAMPOS, 1922, p. X]) a literatura queirosiana. No mesmo prefácio, o antologista creditava os méritos literários de Eça ao seu "sangue português" (CAMPOS, 1922, p. X) à sua "humanidade cristã" (CAMPOS, 1922, p. X) e à sua "sujeição ao dever" (CAMPOS, 1922, p. XI), numa clara prefiguração dos valores que Salazar posteriormente apontaria como "indiscutíveis" em seu regime. Na mesma época, iniciativas como a estátua de Eça no Largo Barão de Quintela e a impressão de sua efígie nas notas de 10 escudos associavam mais ainda sua imagem a um passado vago e a certo heroísmo oficialesco, pouco suscetível a polêmicas e indagações. Décadas depois, o pesquisador queirosiano Ernesto Guerra da Cal apontaria que justamente nesses anos anteriores ao Estado Novo a figura de Eça atravessou um "período de esquecimento" (CAL, 1969, p. 69). António Ferro sabia que o despertar de polêmicas sobre o escritor, naquele ano de 1945, era responsabilidade sua, daí seu arrependimento: sem o gesto do SNI, no sentido de celebrar ostensivamente a figura de Eça - inclusive republicando sua obra na íntegra, sem as censuras feitas por Campos - o dissenso não teria explodido. Ferro, que afinal estava naquela noite entre seus amigos do "escol", não hesitou em reconhecer sem meias palavras o seu erro (FERRO, 1949, p. 13):

\footnotetext{
A partir de há pouco tempo, é certo, desde há 15 ou 20 anos, a obra de Eça de Queirós parecia-nos já coberta daquela pátina que a imunizava das curiosidades doentias dos leitores doentios de todas as épocas. Julgamos assim que foi, talvez, imprudente libertá-las dessa pátina, limpá-las dessa poeira de quase um século, precipitar, outra vez, as novas gerações para certas páginas de $O$ Primo Basilio ou $A$ Relíquia de sentido já obliterado ou esquecido. (...) Eça de Queirós já era hoje considerado, acima de tudo e para além de tudo, um grande português. Terá sido útil, para a sua glória e para a glória de nossa literatura, misturá-lo de novo com as nossas lutas políticas e religiosas, procurar aliciá-lo, por todas as formas e com todos os pretextos, para o fazer ingressar no MUD ou na União Nacional?
}

Este trecho do discurso, além de não deixar dúvidas quanto ao arrependimento de Ferro em relação às celebrações do centenário, é ainda revelador em um útlimo sentido: trata-se de uma manifestação do rematado cinismo com que o diretor do SNI tratava então a questão das "lutas políticas" em Portugal. O ponto em que Ferro lamenta a 
tentativa de "aliciamento" a que Eça fora submetido faz uma referência à União Nacional (o que se pode chamar de "partido" de Salazar) e ao MUD (Movimento de Unidade Democrática): esse lamento é cínico, não apenas porque como foi dito acima o próprio Ferro tentara "aliciar" Eça para o salazarismo no âmbito das comemorações oficiais, mas, sobretudo, porque Ferro trata a União Nacional e o MUD como forças antagônicas e equivalentes no Portugal de então. A afirmação não tinha lógica alguma, e Ferro sabia disso, pois a União Nacional (a qual ele próprio pertencia) tinha uma força incomparável: havia sido a única organização política permitida no país entre 1933 e 1945, destinava-se unicamente a dar suporte ao regime e era secundada por instituições proto-milicianas, como a Legião Portuguesa e a já citada Mocidade Portuguesa (CALDEIRA, 1986). O Movimento de Unidade Democrática, enquanto isso, nascera no dia 8 de outubro de $1945^{7}$ (portanto apenas quatro meses antes do discurso de Ferro aqui debatido), como o primeiro partido de oposição legal em Portugal desde a implantação do Estado Novo: um partido precário, autorizado a contragosto por Salazar no âmbito das pressões internacionais do pós-guerra, que seria colocado na ilegalidade dali a apenas dois anos. (RABY, 1984)

\section{CONSIDERAÇÕES FINAIS}

O arrependimento de António Ferro diante dos desdobramentos do centenário de Eça de Queirós é relevante aqui na medida em que revela certa eficácia dos trabalhos a respeito do escritor no sentido de produzir uma instância de debate público: exatamente aquilo que o regime mais temia.

A produção dos autores que interpretaram Eça politicamente no contexto do centenário, portanto, não pode ser lida (retomando a crítica de Miguel Real) como algo que falha ao não conseguir ler Eça "ontologicamente" por conta de "preconceito ideológico", mas de fato como uma produção crítica que é bem sucedida naquilo que se propõe: apropriar-se de um autor do passado para desafiar uma ordem monológica vigente. $\mathrm{O}$ fato de que eles tenham partido da obra de Eça para fazer política em um contexto fascista não revela que eles impingiram ao autor de A Relíquia uma "bitola" exterior a ele, mas sobretudo que eles enxergaram em sua obra características que funcionavam bem como armas contra um problema que era, então, urgente. E, a julgar pelo discurso de Ferro, as armas acertaram o alvo e feriram.

Cabe, em um momento posterior desta pesquisa, averiguar mais profundamente de que maneira cada um desses e de outros autores se serviu de "certas páginas" de Eça para seus embates; cabe também investigar, de um ponto de vista literário, quais são as características da escrita de Eça que o fizeram tão apropriável naquele momento. Para já, contudo, encerramos lembrando da célebre oposição estabelecida por Walter Benjamin entre o historiador historicista e aquele que é adepto do materialismo histórico:

\footnotetext{
${ }^{7}$ Esta data de nascimento considera apenas a existência legal do MUD, e com esse nome. É preciso ressaltar, contudo, que o MUD é herdeiro de uma outra organização (esta considerada ilegal pelo Estado Novo) que atuou em Portugal ainda durante os anos finais da Segunda Guerra Mundial: o MUNAF (Movimento de Unidade Nacional Antifascista).
} 
intelectuais como Mário Sacramento, Gaspar Simões e Vieira de Almeida não são historicistas, no sentido de que não se interessam por conhecer o passado (no caso, Eça e sua obra) "como ele realmente foi" (BENJAMIN, 1987). Sabendo que essa empreitada não só é impossível como é também estéril, todos eles (embora possuindo variados matizes políticos e advindo de diferentes disciplinas do saber) operam como materialistas históricos, no sentido benjaminiano do termo: eles recorrem a Eça como quem quer "apropriar-se de uma reminiscência, tal como ela relampeja no momento de um perigo" (BENJAMIN, 1987).

\section{REFERÊNCIAS}

ALMEIDA, F. Vieira de. À Jànela de Tormes. Lisboa, Ed. Ocidente, 1945.

ARENDT, Hannah. Origens do totalitarismo: Antissemitismo, imperialismo, totalitarismo. São Paulo: Companhia das Letras, 1989.

BENJAMIN, Walter. Obras escolbidas. Vol. 1. Magia e técnica, arte e política. Ensaios sobre literatura e história da cultura. Prefácio de Jeanne Marie Gagnebin. São Paulo: Brasiliense, 1987.

CAL, Ernesto da Guerra. Lingua e Estilo de Eça de Queirós. São Paulo: Editora da Universidade de São Paulo, 1969.

CALDEIRA, Arlindo Manuel. "O partido de Salazar: antecedentes, organização e funções da União Nacional (1926-34)”. Análise Social, XXII (94), 1986-5. ', p. 943-977

CAMPOS, Agostinho de. (org. e prefácio). Antologia Portuguesa de Eça de Queirós: selecta para a família e a escola. Rio de Janeiro: livraria Francisco Alves, 1922.

FERRO, António. Eça de Queiroz no Centenário de seu nascimento. Lisboa, 1949.

FERRO, António. "O Ditador e a Multidão" in Entrevistas de António Ferro a Salazar,

Lisboa, Parceria A.M. Pereira, 2003

ITO, Giuliano. “Os três Antónios: a recepção de Eça de Queirós na década de 40, Convergência Lusíada n. 28, julho - dezembro de 2012. pp. 108 - 119.

MEDINA, João. Salazar e os fascistas: a história de um conflito (1932 - 1935). Lisboa: Bertrand, 1978.

MELLO, Allyrio de. Eça de Queiroz̧ o exilado da realidade. Porto: Livraria Tavares Martins, 1945.

MENDES, João. Eça de Queiroz - tipos, estilo, moralidade. Lisboa: pro domo, 1945.

PINTO, António Costa. Os Camisas Aquis: Ideologias, elites e movimentos fascistas em Portugal (1914 - 1945), Lisboa: Estampa, 1994.

RAIMUNDO, Orlando. António Ferro: o inventor do Salaz̧arismo. Alfragide: Publicações

Dom Quixote, 2015

REAL, Miguel. O Último Eça. Lisboa: Quidnovi, 2006.

RIBEIRO, Carla. "Portugal perante as nações: António Ferro e a imagem do país". comunicação apresentada no I Colóquio Internacional «Construção de identidade(s). Globalização e fronteiras», realizado a 11 de Novembro de 2011, pelo CITCEM (Centro 
de Investigação Transdisciplinar, Cultura, espaço e memória), na Faculdade de Letras da Universidade do Porto.

ROSAS, Fernando. Salazar e o poder - a arte de saber durar. Lisboa: Tinta da China, 2018. SACRAMENTO, Mario. Eça de Queirós: uma estética da ironia. Lisboa: Imprensa Nacional Casa da Moeda, 2002.

SALAZAR, António de Oliveira. Discursos. Notas Políticas. (1935 - 1937) Vol. II, Coimbra: Coimbra Editora, 1945.

SANTOS, José. "Breves considerações sobre a recepção de António Oliveira Salazar no panorama intelectual da Nova Ordem dos anos 30". Oficina do Historiador, Porto Alegre, EDIPUCRS, v. 2, n. 9, jul./dez. 2016, pp. 61 - 78.

SCHIRÓ, Luís Bensaja de. "Queiroz, António Alberto Eça de." in MATOS, António Campos (org). Dicionário de Eça de Queirós. Lisboa: Imprensa Nacional Casa da Moeda, 2015. p. 1102.

SIMÕES, João Gaspar. Eça de Queirós: O homem e o artista. Lisboa: Dois Mundos, 1945.

SIMPSON, Duncan. A Igreja Católica e o Estado Novo Salazarista, Lisboa, Edições 70, 2014. TORGAL, Luís Reis. Estados novos, estado novo: ensaios de história política e cultural vol. II.

Coimbra: Imprensa da Universidade de Coimbra, 2009.

TRINDADE, Luis. O Estranho caso do Nacionalismo Português - O salazarismo entre a literatura e a politica. Lisboa: Imprensa de Ciências Sociais, 2008.

VICHINSKI, Flávio Garcia. Os Lusíadas para os "lusitos": o destino do épico camoniano no liceu português e a interferência do Estado Novo. 2015. 273 fl. Tese (doutorado) - Faculdade de Letras, Universidade de São Paulo, São Paulo, 2015.

VICTORINO, José Guilherme. "Propaganda e controlo mediático no primeiro salazarismo: a complementaridade de actuação entre o SPN e o aparelho censório", Media \& Jornalismo N.23, Vol.12, N.1 - Outono/Inverno, 2013

VOUILLOT, Eunice Malaquias. Mário Sacramento (1920-1969) : vida e pensamento : sementes de liberdade. Lisboa: Campo da Comunicação, 2011. 